\title{
DUKUNGAN SOSIAL DAN HUBUNGANNYA DENGAN IDE BUNUH DIRI PADA MAHASISWA RANTAU
}

\author{
Alifia Salsabhilla ${ }^{1}$, Ria Utami Panjaitan ${ }^{1}$ \\ ${ }^{1}$ Fakultas Ilmu Keperawatan Universitas Indonesia \\ salsabhillalifia@gmail.com
}

\begin{abstract}
ABSTRAK
Mahasiswa rantau mengalami berbagai perubahan dalam kehidupannya. Dimulai dari perbedaan kebudayaan, perpisahan dengan keluarga, serta adaptasi dengan lingkungan kampus. Ketidakmampuan mahasiswa untuk beradaptasi dapat berdampak pada masalah kesehatan jiwa seperti ide bunuh diri. Dukungan sosial yang rendah dapat menjadi salah satu faktor yang dapat menyebabkan munculnya ide bunuh diri pada mahasiswa rantau. Penelitian ini bertujuan untuk mengetahui hubungan dukungan sosial dengan ide bunuh diri pada mahasiswa rantau Universitas Indonesia khususnya yang berasal dari daerah Jawa Tengah. Metode penelitian menggunakan desain penelitian analitik korelatif dengan pendekatan cross sectional pada 239 mahasiswa rantau. Instrumen pada penelitian ini adalah kuesioner Multidimensional Scale of Perceived Social Support (MSPSS) untuk sumber dukungan sosial serta Suicide Ideation Scale (SSI) untuk ide bunuh diri. Analisis data yang digunakan yaitu analisa univariat dan bivariat dengan uji korelasi gamma. Uji korelasi gamma digunakan untuk melihat ada tidaknya hubungan serta kekuatan hubungan pada dua variabel yang setingkat. Hasil penelitian menunjukkan ada hubungan signifikan dengan kekuatan sedang antara dukungan sosial dengan ide bunuh diri pada mahasiswa rantau dengan nilai $p$ value yaitu 0,000 ( $p$ value $\leq 0,05, \mathrm{r}=-0,533$ ). Skrining kesehatan mental, pendidikan kesehatan, dan meningkatkan dukungan sosial perlu dilakukan untuk mempertahankan status kesehatan mental serta mencegah munculnya masalah ide bunuh diri pada mahasiswa rantau.
\end{abstract}

Kata kunci: Dukungan sosial, ide bunuh diri, mahasiswa rantau

\section{SOCIAL SUPPORT AND ITS RELATIONSHIP WITH THE SUICIDE IDEAS AMONG MIGRANT STUDENTS}

\begin{abstract}
Migrant students experience various changes in their lives. Starting from cultural differences, separation from family, and also adaptation to the campus environment. The inability of students to adapt can have an impact on mental health problems such as suicide ideas. Low social support can be one of the factors that can lead to the idea of suicide in migrant students. This research was conducted to find the correlation between social support and suicide ideas among migrant students at Universitas Indonesia, especially those from Central Java. The methodology of this research is correlative analytic research design with a cross sectional approach to 239 migrant students. The instrument in this study was Multidimensional Scale of Perceived Social Support (MSPSS) questionnaire for sources of social support and the Suicide Ideation Scale (SSI) for suicide ideas. Data analysis used is univariate and bivariate analysis with gamma correlation test. The gamma correlation test is used to see whether there is a correlation and the strength of the correlation on two equal variables. The result of this research shows the significant correlation with medium strength between social support and suicide ideas among migrant students with a $p$ value of 0,000 ( $p$ value $\leq$ $0.05, r=0,533)$. Mental health screening, health education, and increasing social support need to be done to maintain mental health status and prevent the suicide ideas problems among migrant students.
\end{abstract}

Keywords:social support, suicide ideas, migrant students 


\section{PENDAHULUAN}

Bunuh diri adalah penyebab kematian nomor 3 pada generasi muda (Stuart, 2013). Angka bunuh diri pada pemuda telah menjadi tiga kali lebih besar dalam 30 tahun terakhir (Stuart, 2013). Indonesia menempati urutan ke 8 diantara negara ASEAN sebagai negara dengan tingkat bunuh diri yang tinggi (WHO, 2016). Salah satu populasi yang rentan terhadap percobaan dan ide bunuh diri adalah populasi muda. Mahasiswa yang mengalami transisi dari masa remaja ke dewasa awal termasuk ke dalam populasi yang berisiko tersebut. Mahasiswa yang merantau dan merindukan kampung halaman, keluarga, serta temantemannya dapat memiliki gejala depresi dengan ide bunuh diri yang menonjol (Gonçalves, Sequeira, Duarte, \& Freitas, 2014).Sering sendiri dan jauh dari rumah, mahasiswa rantau dapat mengalami rehat signifikan dari jaringan dukungan sosial mereka (Gonçalves, Sequeira, Duarte, \& Freitas, 2014). Memasuki pendidikan tinggi sering membawa masalah psikologikal, termasuk terpisah dari jaringan dukungan sosial yang sudah terbentuk sebelumnya. Mahasiswa yang meninggalkan rumah mereka dapat merasadukungan sosial dan psikologi yang kurang dari orang lain yang mereka anggap dekat dengan mereka, dimana hal ini dapat menjadi implikasi negatif pada kesehatan jiwa dan proses adaptasi mereka (Gonçalves, Sequeira, Duarte, \& Freitas, 2014).

Banyak penelitian yang menemukan pengaruh dukungan sosial atau jaringan dukungan sosial pada kesehatan jiwa dan perannya sebagai moderator atau prediktor perilaku bunuh diri (Bouteyre, Maurel \& Bernard, 2006; Gonçalves, Sequeira, Duarte, \& Freitas, 2014). Persepsi dukungan sosial dan ikatan yang terbangun diantara individu dan sistem sosial dapat menolong adaptasi terhadap situasi stres (Gonçalves, Sequeira, Duarte, \& Freitas, 2014). Mahasiswa dengan jaringan dukungan sosial cukup akan lebih mudah dalam mengembangkan strategi koping terhadap situasi yang tidak bersahabat. Di sisi lain, lemahnya dukungan sosial/keluarga seringkali diasumsikan sebagai faktor risiko lebih tingginya perilaku bunuh diri (Walsh \& Eggert, 2007; Gonçalves, Sequeira, Duarte, \& Freitas, 2014). Dukungan sosial selain sebagai faktor protektif diri, dukungan sosial juga dapat menjadi sumber koping yang dapat membuat mahasiswa merasa lebih berarti, disayangi, dan diperhatikan oleh orang di sekitarnya (Triana, 2018).

Penelitian ini bertujuan untuk mengetahui hubungan dukungan sosial dengan ide bunuh diri pada mahasiswa rantau. Penelitian ini diharapkan dapat menjadi perhatian bagi perawat, mahasiswa, serta pihak kampus bahwa peningkatan dukungan sosial pada mahasiswa rantau penting untuk dilakukan.

\section{METODE}

Penelitian ini menggunakan desain penelitian analitik korelatif dengan pendekatan cross sectional pada 239 mahasiswa rantau (stratified sampling)di Universitas Indonesia dan menggunakan analisa data univariat serta bivariat. Analisa bivariat dilakukan dengan uji korelasi gamma untuk menentukan ada tidaknya hubungan antara dukungan sosial dengan ide bunuh diri. Etika penelitian yang diterapkan adalah menghormati harkat dan martabat manusia, menghormati privasi dan kerahasiaan subjek penelitian, keadilan dan keterbukaan, serta memperhitungkan manfaat dan kerugian yang ditimbulkan. Penelitian ini telah melalui proses kaji etik dan dinyatakan lolos kaji etik oleh Komite Etik Penelitian Fakultas Ilmu Keperawatan Universitas Indonesia.

Pengumpulan data menggunakan dua instrumen yaitu kuesioner Multidimensional Scale of Perceived Social Support (MSPSS) untuk mengidentifikasi persepsi dukungan sosial dan Suicide Scale Ideation (SSI) untuk mengukur ide bunuh diri. Dukungan sosial yang dianalisa terdiri dari tiga sumber yaitu keluarga, teman, dan significant others. Klasifikasi ide bunuh diri terbagi menjadi tiga yaitu tidak ada ide, ide lemah, dan ide sedang hingga kuat. Data diolah dengan langkah editing, coding, data entry, dan cleaning. Kemudian data dianalisis dengan analisa univariat dengan tendensi sentral serta frekuensi dan persentase dan analisa bivariat menggunakan uji korelasi gamma.

\section{HASIL}

Hasil penelitian ini mengenai karakteristik responden didapatkan rata-rata usia responden 19,85 tahun. Responden berjenis kelamin lakilaki berjumlah 69 orang $(28,9 \%)$ dan perempuan 170 (71,1\%). Asal paguyuban paling banyak dari Perhimak Kebumen 
sejumlah 56 orang $(23,4 \%)$ dan paling sedikit dari Pasir Rembang sejumlah 2 orang $(0,8 \%)$. Asal fakultas paling banyak dari Fakultas Ilmu Keperawatan sejumlah 35 orang $(14,6 \%)$ dan paling sedikit dari Fakultas Kedokteran Gigi sejumlah 3 orang $(1,3 \%)$. Angkatan atau tahun masuk paling banyak berasal dari angkatan 2018 sejumlah 81 orang $(33,9 \%)$ dan paling sedikit dari angkatan 2015 sejumlah 44 orang $(18,4 \%)$. Rata-rata lama merantau responden 2,76 tahun. Responden yang tinggal di kost/kontrakkan berjumlah 141 orang (59\%), tinggal di asrama 72 orang (30,1\%), dengan saudara 15 orang $(6,3 \%)$, dan lainnya 11 orang $(4,6 \%)$. Dukungan sosial pada penelitian ini terbagi menjadi dua kategori, yaitu rendah dan tinggi berdasarkan nilai cut of point median dikarenakan persebaran data tidak normal yaitu pada dukungan sosial total 56, dukungan sosial keluarga 20, dukungan sosial teman 19, dukungan sosial significant others 17.

Persentase responden dengan dukungan sosial rendah sebanyak $53,6 \%$ dan dukungan sosial tinggi $46,4 \%$.Responden dengan dukungan sosial keluarga rendah $54,8 \%$ dan dukungan sosial keluarga tinggi 45,2\%. Responden dengan dukungan sosial teman rendah $56,9 \%$ dan dukungan sosial teman tinggi $43,1 \%$. Responden dengan dukungan sosial significant others rendah $51,9 \%$ dan tinggi $48,1 \%$. Hasil analisa ide bunuh diri pada mahasiswa rantau didapatkan responden paling banyak tidak memiliki ide bunuh diri 53,1\% dan memiliki ide bunuh diri kuat 46,9\%. Analisa hubungan antara dukungan sosial (keluarga, teman, dan significant others)dengan ide bunuh diri dicantumkan dalam tabel 1 sampai 4.

Pada tabel 1 hasil uji statistik diketahui adanya hubungan yang signifikan antara dukungan sosial dan ide bunuh diri pada mahasiswa rantau dari paguyuban daerah Jawa Tengah dengan $p$ value yaitu 0,000 . Pada tabel 2 hasil uji statistik didapatkan nilai $\mathrm{p}$ sebesar 0,000 yang berarti terdapat hubungan yang signifikan antara dukungan sosial bersumber dari keluarga dengan ide bunuh diri. Hasil analisa data dari tabel 3 diketahui bahwa ada hubungan antara dukungan sosial teman dengan ide bunuh diri pada mahasiswa rantau paguyuban daerah Jawa Tengah dengan $\mathrm{p}$ value 0,000 . Pada tabel 4 menunjukkan bahwa ada hubungan antara dukungan sosial significant others dengan ide bunuh diri pada mahasiswa rantau paguyuban daerah Jawa Tengah dengan $p$ value 0,009.

Tabel 1.

Hubungan dukungan sosial dengan ide bunuh diri pada mahasiswa rantau $(\mathrm{n}=127)$

\begin{tabular}{|c|c|c|c|c|c|c|c|}
\hline \multirow{3}{*}{ Dukungan Sosial } & \multicolumn{4}{|c|}{ Ide Bunuh Diri } & \multirow{2}{*}{\multicolumn{2}{|c|}{ Total }} & \multirow{2}{*}{$P$ value } \\
\hline & \multicolumn{2}{|c|}{ Tidak Ada Ide } & \multicolumn{2}{|c|}{ Ide Kuat } & & & \\
\hline & $\mathrm{f}$ & $\%$ & $\mathrm{f}$ & $\%$ & $\mathrm{f}$ & $\%$ & \\
\hline Rendah & 51 & 40,15 & 77 & 68,75 & 128 & 53,55 & 0,000 \\
\hline Tinggi & 76 & 59,84 & 35 & 31,25 & 111 & 46,44 & \\
\hline
\end{tabular}

Tabel 2.

Hubungan dukungan sosial keluarga dengan ide bunuh diri pada mahasiswa rantau

\begin{tabular}{|c|c|c|c|c|c|c|c|}
\hline \multirow{3}{*}{$\begin{array}{l}\text { Dukungan Sosial } \\
\text { Keluarga }\end{array}$} & \multicolumn{4}{|c|}{ Ide Bunuh Diri } & \multirow{2}{*}{\multicolumn{2}{|c|}{ Total }} & \multirow[b]{2}{*}{$P$ value } \\
\hline & \multicolumn{2}{|c|}{ Tidak Ada Ide } & \multicolumn{2}{|c|}{ Ide Kuat } & & & \\
\hline & $\mathrm{f}$ & $\%$ & $f$ & $\%$ & $f$ & $\%$ & \multirow{3}{*}{0,000} \\
\hline Rendah & 52 & 40,95 & 77 & 70,54 & 131 & 54,81 & \\
\hline Tinggi & 75 & 59,05 & 35 & 29,46 & 108 & 45,19 & \\
\hline
\end{tabular}

Tabel 3.

Hubungan dukungan sosial teman dengan ide bunuh diri pada mahasiswa rantau $(\mathrm{n}=127)$

\begin{tabular}{|c|c|c|c|c|c|c|c|}
\hline \multirow{3}{*}{$\begin{array}{c}\text { Dukungan Sosial } \\
\text { Teman }\end{array}$} & \multicolumn{4}{|c|}{ Ide Bunuh Diri } & \multirow{2}{*}{\multicolumn{2}{|c|}{ Total }} & \multirow{2}{*}{$P$ value } \\
\hline & \multicolumn{2}{|c|}{ Tidak Ada Ide } & \multicolumn{2}{|c|}{ Ide Kuat } & & & \\
\hline & $\mathrm{f}$ & $\%$ & $\mathrm{f}$ & $\%$ & $\mathrm{f}$ & $\%$ & \\
\hline Rendah & 54 & 42,52 & 82 & 73,21 & 136 & 56,90 & 0,000 \\
\hline Tinggi & 73 & 57,48 & 30 & 26,79 & 103 & 43,10 & \\
\hline
\end{tabular}


Jurnal Keperawatan Jiwa Volume 7 No 1 Hal 107 - 114, Mei 2019

FIKKes Universitas Muhammadiyah Semarang bekerjasama dengan PPNI Jawa Tengah

Tabel 4.

Hubungan dukungan sosial significant others dengan ide bunuh diri pada mahasiswa rantau $(\mathrm{n}=127)$

\begin{tabular}{|c|c|c|c|c|c|c|c|}
\hline \multirow{3}{*}{$\begin{array}{c}\text { Dukungan } \\
\text { SosialSignifi } \\
\text { cant Others }\end{array}$} & \multicolumn{4}{|c|}{ Ide Bunuh Diri } & \multirow{2}{*}{\multicolumn{2}{|c|}{ Total }} & \multirow{2}{*}{$P$ value } \\
\hline & \multicolumn{2}{|c|}{ Tidak Ada Ide } & \multicolumn{2}{|c|}{ Ide Kuat } & & & \\
\hline & $\mathrm{f}$ & $\%$ & $\mathrm{f}$ & $\%$ & $\mathrm{f}$ & $\%$ & \multirow{4}{*}{0,009} \\
\hline Rendah & 56 & 44,09 & 68 & 60,71 & 124 & 51,88 & \\
\hline Tinggi & 71 & 55,91 & 44 & 39,29 & 115 & 48,12 & \\
\hline Jumlah & 127 & 53,14 & 112 & 46,86 & 239 & 100 & \\
\hline
\end{tabular}

\section{PEMBAHASAN}

\section{Hubungan Dukungan Sosial dengan Ide Bunuh Diri}

Hasil dari penelitian ini menunjukkan adanya hubungan negatif antara dukungan sosial dengan ide bunuh diri pada mahasiswa rantau. Senada dengan penelitian ini, menurut penelitian yang dilakukan Endo et al (2014), ditemukan adanya hubungan antara dukungan sosial dengan ide bunuh diri yaitu derajat penerimaan dan pemberian dukungan sosial yang rendah akan meningkatkan keparahan ide bunuh diri yang nantinya juga akan meningkatkan ketidakpuasan yang kuat terhadap dukungan sosial yang dimunculkan. Penelitian yang dilakukan Faria et al (2019) pada individu yang bekerja dengan yang tidak bekerja juga menunjukkan hubungan negatif dengan tiga dimensi dukungan sosial yaitu keluarga, teman dan significant others di kedua kelompok responden.

Penelitian lain yang dilakukan oleh Shenouda \& Basha (2014) pada 293 mahasiswa di Mesir menyatakan bahwa ada hubungan negatif antara dukungan sosial dengan bunuh diri. Hal tersebut juga dibuktikan dengan hasil penelitian pada mahasiswa yang tergabung dalam organisasi atau kelompok yang menunjukkan lebih sedikit memiliki ide bunuh diri (Hassan \& Barrios, 1999; Levine \& Stock, 2016). Penelitian sebelumnya juga mengatakan bahwa dukungan sosial dapat mengurangi stres yang disebabkan perpindahan dari satu daerah ke daerah lain (Ritsner, Modai \& Ponizovsky, 2000; Bhochhibhoya, Dong, \& Branscum, 2017).

Kurangnya dukungan sosial dalam tahap perkembangan mahasiswa yaitu dewasa awal menjadi salah satu faktor risiko adanya ide bunuh diri (Kimbrough, Molock, \& Walton, 2016). Kurangnya memanfaatkan pelayanan kesehatan jiwa dan dukungan sosial dapat menyebabkan mahasiswa rantau mengalami berbagi masalah kesehatan jiwa berat tanpa disadari (Bhochhibhoya, Dong, \& Branscum, 2017). Hal tersebut dikarenakan jaringan sosial dapat memberikan seorang individu pengalaman positif dan kelompok yang memiliki peran untuk menerima dukungan dari lingkungan (Shenouda \& Basha, 2014). Jenis dukungan ini berhubungan dengan kebahagiaan, stabilitas dalam situasi hidup, dan menyadari pentingnya diri sendiri (Cohen \& Wills, 1985; Shenouda \& Basha, 2014).

\section{Hubungan Dukungan Sosial Keluarga dengan Ide Bunuh Diri}

Penelitian ini menunjukkan bahwa adanya hubungan negatif antara dukungan sosial yang bersumber dari keluarga dengan ide bunuh diri. Penelitian yang dilakukan Tabaac, Perrin, \& Rabinovitch (2016) juga menunjukkan bahwa dukungan sosial keluarga memiliki hubungan yang unik dan berkebalikan dengan adanya ide bunuh diri di masa lampau serta percobaan bunuh diri yang pernah dilakukan selama hidup. Penelitian lain yang dilakukan Liu (2011) pada pemuda Asia juga menunjukkan adanya hubungan signifikan yang negatif antara dukungan sosial keluarga dengan ide bunuh diri.

Penelitian lain yang dilakukan oleh Arria et al (2009) juga menunjukkan bahwa ada peran dukungan keluarga dalam ide bunuh diri pada mahasiswa. Penelitian lain yang dilakukan oleh Kimbrough, Molock \& Walton (2016) tentang persepsi dukungan sosial dengan ide bunuh diri pada mahasiswa Afrika-Amerika menunjukkan bahwa mahasiswa yang mempersepsikan keluarganya tidak suportif akan lebih terindikasi mengalami ide bunuh diri. Penelitian senada oleh Consoli et al (2013) tentang perilaku bunuh diri pada remaja depresi mengatakan bahwa hubungan yang kurang baik dengan salah satu orang tua atau dengan kedua orang tua meningkatkan risiko bunuh diri dengan atau tanpa depresi. 
Keluarga adalah sumber dukungan primer yang dihubungkan dengan rendahnya ide bunuh diri (Cenkseven- nder, 2018). Walaupun teman dan significant others adalah sumber dukungan penting bagi mahasiswa, dukungan keluarga adalah sumber yang lebih penting terutama dalam situasi traumatik (Lai \& Ma, 2016). Rojas et al (2017) melaporkan baik ide bunuh diri maupun percobaan bunuh diri memiliki hubungan dengan kurangnya dukungan dari keluarga khususnya orang tua. Menurut Shaheen \& Jahan (2017) kelompok dengan dukungan keluarga rendah memiliki peningkatan dalam ide bunuh diri di bawah kondisi stress. Dukungan sosial dari keluarga menunjukkan hubungan yang lebih berjangka panjang dan konsisten dengan penurunan ide bunuh diri dibanding dukungan sosial dari significant others yang dapat menghilang dengan lebih cepat (Tabaac, Perrin, \& Rabinovitch, 2016).

Dukungan sosial keluarga dapat memengaruhi ide bunuh diri dikarenakan keluarga merupakan hubungan yang lebih berjangka panjang daripada sumber dukungan sosial yang lainnya. Keluarga yang suportif akan membuat mahasiswa merasa didukung sehingga tidak merasakan stres yang dapat memicu adanya ide bunuh diri. Penyebab lainnya keluarga memengaruhi ide bunuh diri adalah karena keluarga merupaka pemberi dukungan primer dimana setiap individu mengharapkan keluarga sebagai sumber yang pertama kali memberikan dukungan dibandingkan sumber dukungan sosial lainnya seperti teman dan significant others.

\section{Hubungan Dukungan Sosial Teman dengan Ide Bunuh Diri}

Pada penelitian ini didapatkan bahwa dukungan sosial teman memiliki hubungan yang negatif dengan ide bunuh diri. Berdasarkan penelitian yang dilakukan Páramo et al (2014) tentang dampak dukungan sosial pada penyesuaian belajar mahasiswa tahun pertama di Spanyol menunjukkan dukungan sosial bersumber dari teman memiliki kekuatan yang lebih dari dukungan sosial bersumber dari keluarga. Hal ini dikarenakan mahasiswa lebih bergantung pada teman yang terlihat sebagai sumber dukungan yang lebih efektif dikarenakan mengalami stressor yang sama serta dapat memberikan dukungan yang lebih baik dimana orang tua atau keluarga tidak dapat memberikannya (Tao et al., 2000; Páramo, Martinez, Tinajero, \& Rodriguez, 2014)

Dukungan sosial dari teman memiliki hubungan dengan menurunnya risiko bunuh diri dibuktikan dalam dua penelitian yang dilakukan oleh Irwin \& Austin (2013) dan Tabaac, Perrin, \& Rabinovitch (2016). Menurut Tabaac, Perrin, \& Rabinovitch (2016) dukungan sosial dari teman memiliki peran yang lebih sedikit dibanding dukungan sosial dari keluarga dan significant others pada penurunan ide bunuh diri. Berbicara dengan teman tentang masalah yang dihadapi memiliki hubungan dengan penurunan ide bunuh diri pada pemuda Asia dan Eropa (Liu, 2011). Individu dengan kepuasan akan hidup rendah, keputusasaan tinggi, dan depresi umumnya memiliki persepsi dukungan sosial dari teman yang rendah (Kong, et al., 2012). Masalah tersebut jika tidak ditangani juga dapat mengarah ke ide bunuh diri.

Menurut Buote et al (2008) hubungan pertemanan dapat membantu penyesuaian mahasiswa terhadap lingkungan kampus bahkan menimbulkan ikatan dengan universitas dan penyesuaian akademik. Hal tersebut akan membantu dalam mengurangi stress mahasiswa sehingga dapat terhindar dari munculnya ide bunuh diri. Menurut Bearman \& Moody (2004) lingkungan pertemanan memberikan dampak pada risiko bunuh diri terutama remaja perempuan yang mengalami peningkatan ide bunuh diri saat dalam kondisi isolasi sosial dan pola pertemanan yang kurang baik. Pelajar yang mengalami isolasi sosial atau dukungan sosial teman yang rendah menunjukkan peningkatan risiko perilaku bunuh diri (Westefeld, et al., 2010; National Youth Mental Health Foundation, 2017).

Pada mahasiswa rantau teman merupakan sumber dukungan sosial yang penting dikarenakan teman merupakan individu yang melalui tahap perkembangan yang sama sehingga stressor yang dihadapi pun umumnya sama. Berbagi cerita serta melewati masalah bersama membuat teman menjadi sumber dukungan sosial yang jika kurang maka akan menyebabkan stres dan dalam jangka panjang 
dapat menyebabkan ide bunuh diri pada mahasiswa rantau.

\section{Hubungan Dukungan Sosial Significant Others dengan Ide Bunuh Diri}

Berdasarkan hasil analisis data didapatkan bahwa ada hubungan negatif antara dukungan sosial significant others dengan ide bunuh diri. Dukungan sosial dari significant others memiliki hubungan berkebalikan dengan ide bunuh diri (Tabaac, Perrin, \& Rabinovitch, 2016). Hal tersebut sesuai dengan hasil penelitian ini dimana responden yang memiliki dukungan sosial significant others rendah lebih banyak yang memiliki ide bunuh diri kuat dibanding yang tidak memiliki ide bunuh diri. Sebuah penelitian yang dilakukan Ingvar \& jehagen (1999) kepada pasien dengan riwayat bunuh diri dan significant others yang dimilikinya menunjukkan pentingnya peran significant others dalam memantau keadaan pasien setelah dirawat akibat percobaan bunuh diri.

Mahasiswa yang merantau mungkin mengalami kontak yang berkurang dengan significant others yang dimilikinya dari kelompok sosial yang lama atau yang berasal dari daerah aslinya setelah mereka merantau dan khususnya untuk mahasiswa tahun pertama mungkin belum membangun jaringan sosial dengan significant others yang baru sehingga kekuatan hubungan antara ide bunuh diri dan significant others lemah (Lai \& Ma, 2016). Hal tersebut senada dengan hasil penelitian ini dimana kekuatan hubungan antara dukungan sosial significant others dengan ide bunuh diri memiliki kekuatan yang paling lemah dibandingkan hubungan dukungan sosial sumber lain dengan ide bunuh diri. Holt et al (2014) mengatakan bahwa faktor yang dapat menyebabkan remaja memiliki ide bunuh diri adalah masalah hubungan, krisis yang sedang dialami, masalah kesehatan jiwa, dan masalah dengan pasangan.

Berkurangnya kontak dengan significant others dari tempat asal serta belum berhasilnya membangun hubungan dengan significant others di tempat yang baru pada mahasiswa rantau menjadi alasan lemahnya hubungan ide bunuh diri dengan dukungan sosial significant others. Kurangnya dukungan ini tentu dapat menjadi faktor munculnya ide bunuh diri pada mahasiswa rantau dimana significant others memiliki peran penting dalam memantau keadaan kejiwaan seseorang.

\section{SIMPULAN DAN SARAN Simpulan}

Hasil penelitian ini menjelaskan bahwa ada hubungan antara dukungan sosial (dari sumber keluarga, teman, dan significant others) dengan ide bunuh diri.

\section{Saran}

Diperlukan adanya upaya pencegahan untuk ide bunuh diri pada mahasiswa rantau seperti skrining kesehatan mental, pendidikan kesehatan, dan meningkatkan dukungan sosial untuk mencegah terjadinya tindakan lanjut yang muncul dari ide bunuh diri seperti percobaan bunuh diri.

\section{DAFTAR PUSTAKA}

Bearman, P., \& Moody, J. (2004). Suicide and Friendships among American Adolescents. American Journal of Public Health, 89-95.

Bhochhibhoya, A., Dong, Y., \& Branscum, P. (2017). Sources of Social Support Among International College Students in the United States. Journal of International Students, Vol 7, Issue 3, 671-686.

Cenkseven- nder, F. (2018). Social Support and Coping Styles in Predicting Suicide Probability among Turkish Adolescents. Universal Journal of Educational Research, 145-154.

Consoli, A., Peyre, H., Speranza, M., Hassler, C., Falissard, B., Touchette, E., . . . Revah-Levy, A. (2013). Suicidal Behaviors in Depressed Adolescents: Role of Perceived Relationships in The Family. Child and Adolescent Psychiatry Mental Health, 1-12.

Endo, G., Hirokazu, T., Fukuoka, Y., Aiba, M., Nemoto, K., Shiratori, Y., . . . Asada, T. (2014). How Perceived Social Support Relates to Suicidal Ideation: A Japanese Social Resident Survey. International Journal of Social Psychiatry, 290-298. 
Faria, M., Maria, S., Sargento, P., \& Branco, M. (2019). The Role of Social Support in Suicidal Ideation: A Comparison of Employed vs Unemployed People. Journal of Mental Health, 1-8.

Gonçalves, A., Sequeira, C., Duarte, J., \& Freitas, P. (2014). Suicide Ideation in Higher Education Students: Influence of Social Support. Atención Primaria, 8891.

Kimbrough, R. M., Molock, S. D., \& Walton, K. (2016). Perception of Social Support, Acculturation, Depression, and Suicidal Ideation among African American College Students at Predominantly Black and Predominantly White Universities. Journal of Negro Education, 295-307.

Lai, C., \& Ma, C. (2016). The Mediating Role of Social Support in The Relationship Between Psychological Well-Being and Health-Risk Behaviors among Chinese University Students. Health Psychology Open, 1-11.

Levine, H., \& Stock, S. R. (2016). College Student Mental Health. Hanover: Wiley Periodicals.

Páramo, M. F., Martinez, Z., Tinajero, C., \& Rodriguez, M. S. (2014). The Impact of Perceived Social Support in Firs-Year Spanish College Student Adjustment. Journal of International Scientific Publications, 289-300.

Rojas, S., Bilsky, S., Dutton, C., Badour, C., Teldner, M., \& Leen-Feldner, E. (2017). Lifetime Histories of PTSD, Suicidal Ideation, and Suicide Attempts in Nationally Representative Sample of Adolescents: Examining Indirect Effects viaThe Roles of Family and Peer Social Support. Journal of Anxiety Disorders, 95-103.

Shaheen, H., \& Jahan, M. (2017). Student Stress and Suicidal Ideation: The Role of Social Support From Family, Friends, and Significant Others. International Journal of Humanities and Social Science Invention, 21-32.
Shenouda, E. N., \& Basha, S. E. (2014). Resilience, Social Support, and Stress as Predictors of Suicide Ideation among Public Universities' Students in Egypt. International Journal of Sustainable Development, 37-66. 
Jurnal Keperawatan Jiwa Volume 7 No 1 Hal 107 - 114, Mei 2019

FIKKes Universitas Muhammadiyah Semarang bekerjasama dengan PPNI Jawa Tengah 